\title{
Analysis of Single Nucleotide Polymorphism rs9939609 in FTO Gene of Obese Males in Iraqi Population
}

\author{
Mustafa N. Jumaa ${ }^{1} P h D$, Nahi Y. Yaseen ${ }^{2} P h D$, Adil F. Shehab ${ }^{3} P h D$, Rafid M. Karim ${ }^{4} P h D$, \\ Likaa H. Sagban ${ }^{5} P h D$
}

\begin{abstract}
${ }^{1}$ Dept. of Biology, College of Science, Al-Anbar University, Al-Anbar, Iraq, $\quad{ }^{2}$ Iraqi Center for Cancer and Medical Genetic Research, Al-Mustansiryia University, Baghdad, Iraq, ${ }^{3}$ Dept. of Biology, College of Science, Tikrit University, Tikrit, Iraq, ${ }^{4}$ Marine Science Centre, Basrah University, Basrah, Iraq, ${ }^{5}$ Dept. of Biology, College of Education, Karbala University, Karbala, Iraq
\end{abstract}

\begin{abstract}
Background Obesity is a serious on public health. It contributes in many serious health conditions including high cholesterol, type 2 diabetes, osteoarthritis, high blood pressure, gallbladder disease, coronary heart disease, stroke, respiratory problems ... etc. Polymorphism of TA (rs9939609) in fat mass and obesity associated (FTO) gene was found to be associated with obesity in children and adults according to many studies conducted on populations from Europe, America and Asia. Whether Single nucleotide polymorphism (SNP) rs9939609 is an associated with obesity in Iraqi population remains of concern.

Objective To investigate the polymorphism of rs9939609 SNP in FTO gene and its relationship to the obese males in Iraqi population.

Methods One hundred twenty of males were classified as obese based on body mass index (BMI) with mean age 20-50 year and fifty aged-matched healthy males as a control were included in this study. Lipid profile was estimated by using Spinreact-C€, and an ELISA kit was used to assess the FTO level.

Results The results showed that there are significant differences $P \leq 0.05$ for AA genotype with all parameters whereas TA genotype showed significant differences with most of parameters in revers to TT genotype, which has showed no significant differences with most of parameters. The percentage of TT, TA, AA, alleles were $27.72 \%, 49.86 \%, 22.42 \%$ respectively, also an elevated of TT genotype frequency was observed in healthy compared to obese. On the other hand, the percentage of $\mathrm{T}$ and $\mathrm{A}$ allele frequency were $52.65 \%$ and $\mathbf{4 7 . 3 5 \%}$ respectively. Also, an elevated in serum FTO enzyme level was observed in obese.

Conclusion The presence of A risk allele in the Iraqi population is the cause in the incidence of obesity, which reflected its impact on the BMI and central obesity through the disturbances in lipid profile and FTO enzymes value.

Keywords Single Nucleotide Polymorphism, rs9939609, Obesity, FTO gene.
\end{abstract}

List of abbreviation: FTO = Fat mass and obesity associated gene, $\mathrm{SNP}=$ Single nucleotide polymorphism, $\mathrm{BMI}=$ Body mass index, T2D = Type 2 Diabetes, $\mathrm{CO}=$ central obesity

\section{Introduction}

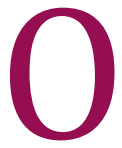
besity can be defined as the biological case that resulted from accumulation of excessive fat or these fats, which little used as a source of bio-energy due to the weakness of human activity or tendency of 
individual to avoid movement, work or environmental interaction ${ }^{(1,2)}$. rs9939609 is a Single Nucleotide Polymorphism (SNP), which is located in the first intron of Fat mass and obesity associated (FTO) gene. The AArs9939609 genotype is the most serious one ${ }^{(3)}$. Ten different SNPs were identified in the first intron of FTO gene and they have related to body mass index (BMI) and Type 2 Diabetes (T2D) ${ }^{(4)}$. It was found that the increasing in $\mathrm{BMI}$ is associated with rs9939609 (A) carriers in patients with Type 1 Diabetes (T1D) but not those with diabetic nephropathy ${ }^{(5)}$. Also, Kilpeläinen et al (6) showed that the polymorphism of rs9939609 was related to T2D in east and south Asia similar to that observed in Europe. The studies by Luczynski et al ${ }^{(7)}$ and Liu et al ${ }^{(8)}$ revealed that the polymorphism of this SNP associated with obesity and cardiovascular risk factors. Variant in the FTO gene is predisposes to cause the T2D through an effect on BMI. Furthermore, $16 \%$ of the adults with homozygous for the risk allele had 3 kilograms more and 1.67 fold increased likelihood of obesity as a compared with those not having a risk allele. This correlation was noticed from the age of 7 years onwards and reflects an effect on increasing of fat mass ${ }^{(9)}$. The polymorphism of rs9939609 resulted in an overexpression of FTO gene in Pakistani obese female ${ }^{(10)}$. Many studies showed that the risk allele A of rs9939609 in FTO gene was associated with increase of the BMI and incidence of obesity ${ }^{(11-13)}$. The presence of both risk alleles A and C from rs9939609 in FTO gene and rs17782313 in MC4R gene respectively caused 4-fold increase of obesity risk in childhood and adolescents from Greece origin ${ }^{(14)}$. Luczyoski et al ${ }^{(15)}$ showed that the main factors that caused an increase of BMI in children with Type 1 Diabetes, especially in female gender, are poor metabolic control and carrying the A allele of the rs9939609. Patients with co-infected of human immunodeficiency virus plus Hepatitis C virus (HIV/ HCV) who carry AT/AA genotype of rs9939609 had higher quota of metabolic disturbances and lower probability of response for successful virologic Hepatitis $C$ virus therapy ${ }^{(16)}$. It was found that there is a strong correlation between $A A$ genotype of rs9939609 FTO gene and BMI increasing in deep venous thrombosis patients with or without pulmonary embolism ${ }^{(17)}$. Feng et al ${ }^{(18)}$ observed a significant association in Chinese individuals carrying AA genotype of rs9939609 and increase tuberculosis risk as a compared with genotype TT individuals. In addition, an inverse association was noticed between completed suicide and the rs9939609 $A$ allele which is independent to the correlation between the obesity related A allele of rs9939609 and alcohol addiction ${ }^{(19)}$. Certain Polymorphisms of FTO gene have an effect on regulation of genetic expression related to the susceptibility for cancer ${ }^{(20)}$.

\section{Methods}

One hundred seventy Blood samples (one sample included $4 \mathrm{ml}$ of blood for biochemical analysis and $4 \mathrm{ml}$ of blood for genetic analysis) were collected from men who their ages range from 20-50 years, 120 of them are obese who were classified based on BMI into three groups. Obesity group I (BMI= 30-34.9), obesity group II (BMI= 35-39.9) and obesity group III (BMI= 40 onwards). Other men (50) are apparently healthy and they were grouped as a control (BMI= 18-24.9).

\section{Body measurements}

BMI was calculated by dividing weight by height square (Kilogram/meter ${ }^{2}$ ), while the central obesity $(\mathrm{CO})$ represented by the ratio of the waist circumference to the Hip circumference.

\section{DNA extraction}

The DNA was extracted from blood samples by using DNA isolation kit and according to the procedure provided by manufacturer (Geneaid). 
Genotyping of FTO SNP rs9939609

Polymerase chain reaction (PCR)-touch time technique was used to amplify the FTO SNP rs9939609. The forward (5AACTGGCTCTTGAATGAAATAGGATTCAGA -3) and revers (5AGAGTAACAGAGACTATCCAAGTGCAGTAC) primers were used, the primers were provided by manufacturer (Integrated DNA Technologies, USA). The PCR cycling condition was shown in table (1). For genotyping rs9939609 SNP, Restriction fragment length polymorphism (RFLP) technique by using Sac I restriction enzyme (Biolab, New England) was conducted. The enzyme cuts in sites showed in figure (1), the T allele of the FTO SNP rs9939609 has no site for Sac I whereas the A allele has one site for the enzyme. Therefore, one and two fragments will resulted from treatment of $\mathrm{T}$ and $\mathrm{A}$ alleles by Sac I respectively. Ten $\mu \mathrm{l}$ of reaction mixture contained $5.5 \mu \mathrm{l}$ free nuclease water, $1 \mu \mathrm{l} \mathrm{NE}$ Buffer 1.1, $1 \mu \mathrm{l} \mathrm{Sac} \mathrm{I} \mathrm{and} 2.5 \mu \mathrm{l}(0.3 \mu \mathrm{g})$ of amplified FTO SNP rs9939609. The reaction mixture was then incubated in water bath at $37^{\circ} \mathrm{C}$ for 1 hour. After that, the polyacrylamide gel $(12 \%)$ was run for the product of the cleavage mixtures.

Table 1. PCR cycling condition

\begin{tabular}{cccc}
\hline Cycle step & Temperature & Time & Cycle No. \\
\hline Initial denaturation & $94{ }^{\circ} \mathrm{C}$ & $5 \mathrm{~min}$ & 1 \\
Denaturation & $94{ }^{\circ} \mathrm{C}$ & $45 \mathrm{sec}$ & \\
Annealing & $61{ }^{\circ} \mathrm{C}\left(-0.5^{\circ} \mathrm{C}\right.$ per Cycle $)$ & $45 \mathrm{sec}$ & 20 \\
Extension & $72{ }^{\circ} \mathrm{C}$ & $45 \mathrm{sec}$ & \\
\hline \multicolumn{4}{c}{ The PCR mixture was then applied for cycles below } \\
Cycle step & Temp. & Time & Cycle No. \\
Denaturation & $94{ }^{\circ} \mathrm{C}$ & $45 \mathrm{sec}$ & \\
Annealing & $51^{\circ} \mathrm{C}$ & $45 \mathrm{sec}$ & 15 \\
Extension & $72{ }^{\circ} \mathrm{C}$ & $45 \mathrm{sec}$ & 1 \\
Final extension & $72{ }^{\circ} \mathrm{C}$ & $10 \mathrm{~min}$ & \\
\hline
\end{tabular}

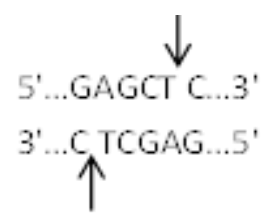

Fig. 1. Restriction sites of Sac I enzyme Parameters estimate

Lipid profile including triglyceride (TG), total cholesterol (TC), high density lipoproteinCholesterol (HDL-C), Low density lipoproteincholesterol (LDL-C) and very low density lipoprotein-cholesterol (VLDL-C) were estimated by using kits from Spinreact-C $\epsilon$. Human Alpha-ketoglutarate-dependent dioxygenase ELISA kit (Cusabio, China) was used to assessment FTO levels.

\section{Statistics Analysis}

The statistical analysis Chi-Square (X2 test) was used to assess the significant differences $(P \leq$ 0.001) between different factors in parameters.

\section{Results}

The present study shows that the $\mathrm{CO}$ was increased by increasing in BMI (figure 2 and 3 ). On the other hand, figure (4) showed the polyacrylamide gel resulted from digestion of 
the FTO SNP rs9939609 by Sac I. The effect of the FTO SNP rs9939609 on other parameters included in this study is demonstrated in table (2).

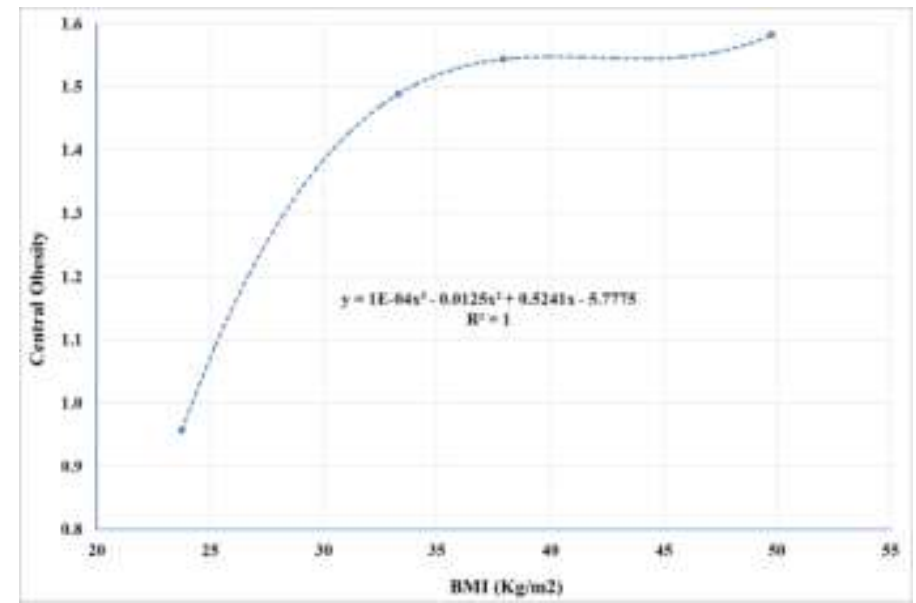

Fig. 2. Relationship between BMI and central obesity

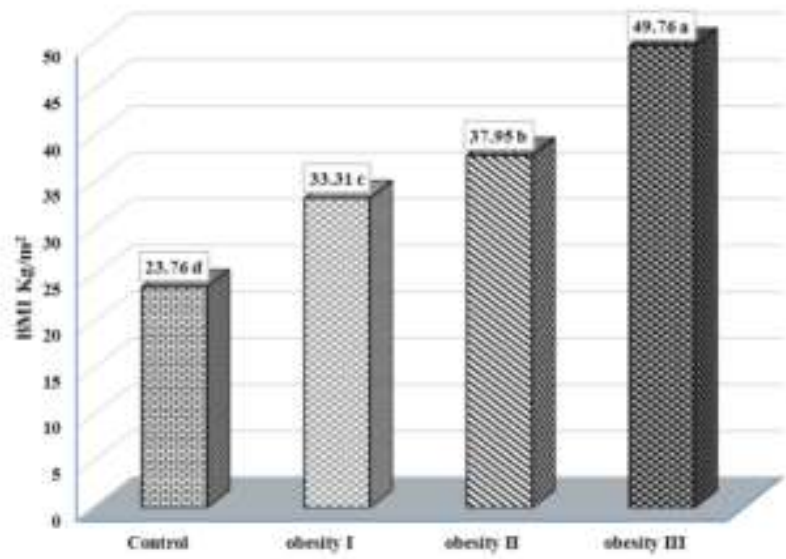

(A)

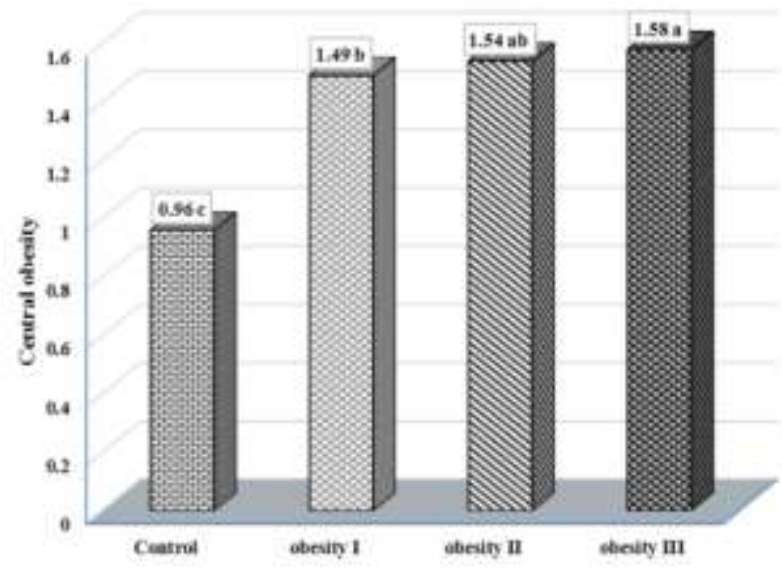

(B)

Fig. 3. BMI (A) and CO (B) among obesity and control groups 


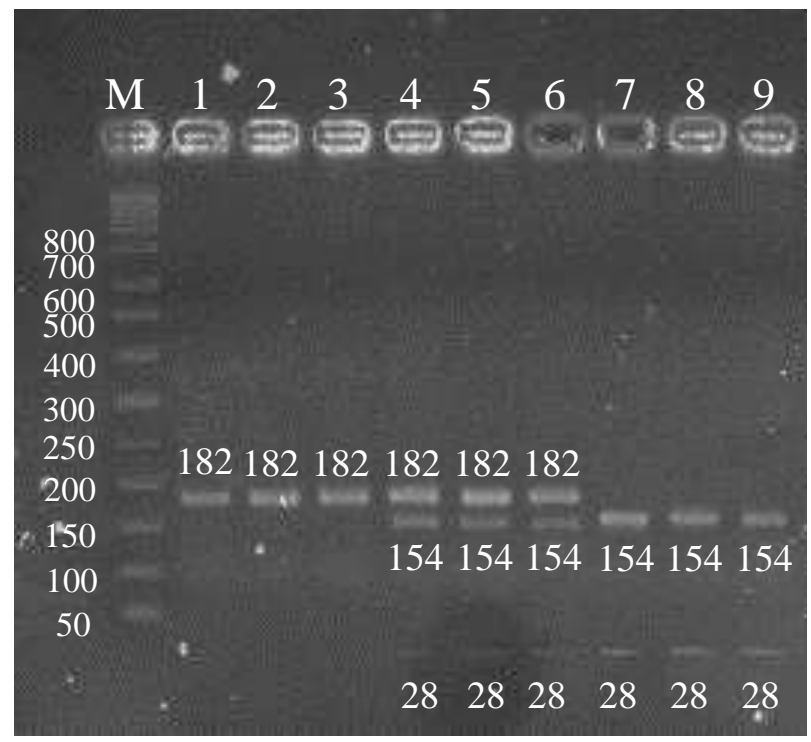

Fig. 4. Analysis of the digested FTO SNP rs9939609 by Sac I on $12 \%$ polyacrylamide. The gel was run for approximately 60 minutes at 80 volts. M: 50 bp DNA ladder; Lanes 1-3: TT (HomozygousWild Type); Lanes 4-6: TA (Heterozygous); Lanes 7-9: AA (Heterozygous).

Table 2. The genetic effects of the FTO SNP rs9939609 on investigated parameters

\begin{tabular}{lccc}
\hline Parameter & $\begin{array}{c}\text { TT } \\
\text { mean } \pm \text { SD }\end{array}$ & $\begin{array}{c}\text { TA } \\
\text { mean } \pm \text { SD }\end{array}$ & $\begin{array}{c}\text { AA } \\
\text { mean } \pm \text { SD }\end{array}$ \\
\hline$B M l \mathrm{Kg} / \mathrm{m}^{2}$ & $24.43 \pm 1.62 \mathrm{c}$ & $35.64 \pm 1.57 \mathrm{~b}$ & $41.54 \pm 1.49 \mathrm{a}$ \\
$\mathrm{CO} . \mathrm{cm}$ & $0.98 \pm 0.12 \mathrm{~b}$ & $1.11 \pm 0.18 \mathrm{~b}$ & $1.55 \pm 0.07 \mathrm{a}$ \\
$\mathrm{TG} \mathrm{mg} / \mathrm{dl}$ & $97.96 \pm 1.69 \mathrm{c}$ & $204.26 \pm 0.98 \mathrm{~b}$ & $236.50 \pm 1.40 \mathrm{a}$ \\
$\mathrm{TC} \mathrm{mg} / \mathrm{dl}$ & $147.52 \pm 1.78 \mathrm{c}$ & $212.09 \pm 1.67 \mathrm{~b}$ & $234.07 \pm 1.77 \mathrm{a}$ \\
$\mathrm{HDL} \mathrm{mg} / \mathrm{dl}$ & $51.29 \pm 1.01 \mathrm{~b}$ & $45.03 \pm 1.14 \mathrm{~b}$ & $33.97 \pm 1.08 \mathrm{a}$ \\
$\mathrm{LDL} \mathrm{mg} / \mathrm{dl}$ & $69.04 \pm 1.44 \mathrm{c}$ & $129.68 \pm 1.17 \mathrm{~b}$ & $147.38 \pm 1.29 \mathrm{a}$ \\
$\mathrm{VLDL} \mathrm{mg} / \mathrm{dl}$ & $18.94 \pm 1.69 \mathrm{c}$ & $39.71 \pm 1.49 \mathrm{~b}$ & $45.21 \pm 1.41 \mathrm{a}$ \\
enzyme FTO & $186.4 \pm 1.7 \mathrm{c}$ & $333.1 \pm 1.9 \mathrm{~b}$ & $390.7 \pm 1.55 \mathrm{a}$ \\
\hline
\end{tabular}

$\mathrm{a}, \mathrm{b}$ and $\mathrm{c}$ are letters used to indicate the significant differences at $\mathrm{P} \leq 0.05$. Different letters mean a statistical significant difference between the 3 different groups for the same parameter. Same letters indicate there is no statistical significant different within the same group for different parameters.

\section{Discussion}

Individuals with normal homozygous (TT) revealed one band of $182 \mathrm{bp}$, while the individuals with heterozygous (TA) and homozygous (AA) revealed three $(182,154$ and $28 \mathrm{bp}$ ) and two (154 and $28 \mathrm{bp}$ ) bands respectively (fig. 4). The results in table (2) showed no significant differences between the genotype $\mathrm{TT}$ and the majority of parameters. By contrast, the genotype TA showed significant differences $(P \leq 0.05)$ with the majority of parameters while the genotype $A A$ has significant differences with all parameters which suggest that the rs9939609 A allele is strongly associated with obesity or in other words, most of the obese are located under the genotype AA. Similarly for genotypes frequency, the results revealed that there are significant differences $(P \leq 0.05)$ among the three genotypes, $27.72,49.86$ and $22.42 \%$ for 
TT, TA and AA respectively. Also, it has been found that the frequency of the genotype TT was elevated in the control as a compared to obesity groups. The frequency of $T$ and $A$ alleles were 52.65 and $47.35 \%$ respectively. Furthermore, it can be noticed from the table (2) that the FTO level increased in genotypes TA and AA suggesting that the risk $A$ allele has an effect on FTO expression causing an overexpression which reflected on the incidence of obesity. This result is coordinated with a study by Berulava and Horsthemke (21) who observed that the A- rs9939609 allele is associated with an overexpression of FTO gene. The current study was also agreed with a study by Chang et al. who showed that the rs9939609 A allele was strongly associated with obesity and $\mathrm{BMI}$ in the Chinese population whereas the allele was most common in the European than in Chinese populations ${ }^{(22)}$. Li et al also showed that the FTO-rs9939609 allele increased BMI by $0.26 \mathrm{~kg} / \mathrm{m}^{2}$ allele, Waist to Hip Ratio (WHR) by 0.003 /allele, body fat percentage by $0.31 \% /$ allele and T2D by 1.15 fold/ allele ${ }^{(6)}$. Likewise, other studies have pointed to the association of rs9939609 polymorphism with fat cell lipolysis, obesity, inflammation and cardiovascular diseases $(3,7,23)$. Yang et al revealed that the BMI, waist and hip circumference, systolic and diastolic pressure, TG and LDL-C were higher, whereas the HDL-C was lower in Chinese children and adolescents with a TA or AA genotype compared to those with TT genotype ${ }^{(13)}$.

The current study has concluded that the obesity in men of Iraqi population were associated with the presence of A risk allele of the rs9939609 FTO gene that resulted in a turbulence in lipid profile and FTO enzyme value.

\section{Acknowledgement}

Many thanks and gratitude goes to the staff of Department of Biology, College of Education University of Tikrit, Tikrit, Iraq for assisting and supporting this research.

\section{Author Contribution}

Authors (1) and (2) made substantial contributions to conception and design, and/or acquisition of data, and/or analysis and interpretation of data.

Authors (3), (4) and (5) participated in drafting the article or revising it critically for important intellectual content. Also, they give final approval of the version to be submitted and any revised version.

\section{Conflict of interest}

The authors declare no conflict of interest.

\section{Funding}

Self-funding.

\section{References}

1. WHO. Obesity and overweight. World Health Organization. 2009 January 10.

2. OECD. Obesity update. Organization of Economic Cooperation and Development. 2012. www.oecd.org/health/fitnotfat.

3. Wåhlén K, Sjölin $E$, Hoffstedt J. The common rs9939609 gene variant of the fat mass- and obesityassociated gene FTO is related to fat cell lipolysis. J Lipid Res. 2008; 49(3): 607-11.

4. Luis DA, De Aller $R$, Conde $R$, et al. Effects of RS9939609 gene variant in FTO gene on weight loss and cardiovascular risk factors after biliopancreatic diversion surgery. J Gastrointest Surg. 2012; 16(1): 1194-8.

5. Gu HF, Alvarsson A, Brismar K. The common FTO genetic polymorphism rs9939609 is associated with increased BMI in type 1 diabetes but not with diabetic nephropathy. Biomarker Insights. 2010; 5(1): 29-32.

6. Li H, Kilpeläinen TO, Liu C, et al. Association of genetic variation in FTO with risk of obesity and type 2 diabetes with data from 96,551 East and South Asians. Diabetologia. 2012; 55(4): 981-95.

7. Luczynski W, Zalewski G, Bossowski A. The association of the FTO rs9939609 polymorphism with obesity and metabolic risk factors for cardiovascular diseases. J Physiol Pharmacol. 2012; 63(3): 241-8.

8. Liu C, Mou S, Pan C. The FTO Gene rs9939609 polymorphism predicts risk of cardiovascular disease: a systematic review and meta-analysis. PLoS One. 2013; 8(8): e71901.

9. Frayling $T M$, Timpson $\mathrm{NJ}$, Weedon $\mathrm{MN}$, et al. $\mathrm{A}$ common variant in the FTO gene is associated with body mass index and predisposes to childhood and adult obesity. Science. 2007; 316(5826): 889-94. 
10. Shahid A, Rana S, Saeed S, et al. Common variant of FTO gene, rs9939609, and obesity in Pakistani females. Biomed Res Int. 2013;2013:324093. doi: 10.1155/2013/324093.

11. Alharbi KK, Richardson TG, Khan IA, et al. Influence of adiposity-related genetic markers in a population of Saudi Arabians where other variables influencing obesity may be reduced. Dis Markers. 2014;2014:758232. doi: 10.1155/2014/758232.

12. Qi Q, Kilpeläinen TO, Downer MK, et al. FTO genetic variants, dietary intake and body mass index: insights from 177330 individuals. Hum Mol Genet. 2014; 23(25): 6961-72.

13. Yang $M, X u Y$, Liang $L$, et al. The effects of genetic variation in FTO rs9939609 on obesity and dietary preferences in Chinese Han children and adolescents. PLoS One. 2014; 9(8): e104574.

14. Lazopoulou N, Gkioka E, Ntalla I, et al. The combined effect of MC4R and FTO risk alleles on childhood obesity in Greece. Hormones (Athens). 2015; 14(1): 126-33.

15. Luczyński W, Fendler W, Ramatowska A, et al. Polymorphism of the FTO gene influences body weight in children with type 1 diabetes without severe obesity. Int J Endocrinol. 2014; 2014:630712. doi: 10.1155/2014/630712.

16. Pineda-Tenor D, Berenguer J, Jiménez-Sousa MA, et al. FTO rs9939609 polymorphism is associated with metabolic disturbances and response to HCV therapy in HIV/HCV-coinfected patients. BMC Med. 2014; 12(1): 198.

17. Klovaite J, Benn M, Nordestgaard BG. Obesity as a causal risk factor for deep venous thrombosis: a Mendelian randomization study. J Intern Med. 2015; 277(5): 573-84.
18. Feng Y, Wang F, Pan H, et al. Obesity-associated gene FTO rs9939609 polymorphism in relation to the risk of tuberculosis. BMC Infect Dis. 2014; 14(1): 592.

19. Chojnicka I, Fudalej S, Walczak A, et al. Inverse association between obesity predisposing FTO genotype and completed suicide. PLoS One. 2014; 9(9): e108900.

20. Hernández-Caballero ME, Sierra-Ramírez JA. Single nucleotide polymorphisms of the FTO gene and cancer risk: an overview. Mol Biol Rep. 2015; 42(3): 699-704

21. Berulava T, Horsthemke B. The obesity-associated SNPs in intron 1 of the FTO gene affect primary transcript levels. Eur J Hum Genet. 2010; 18(9): 10546.

22. Chang YC, Liu PH, Lee WJ, et al. Common variation in the fat mass and and modulates bmi in the Chinese population. Diabetes. 2008; 57(8): 2245-52.

23. Olza J, Ruperez Al, Gil-Campos $\mathrm{M}$, et al. Influence of FTO variants on obesity, inflammation and cardiovascular disease risk biomarkers in Spanish children: a case - control multicentre study. BMC Med Genet. 2013; 14: 123.

\section{Correspondence to Dr. Mustafa N. Jumaa E-mail:m79n2008@yahoo.com \\ Received: $22^{\text {nd }}$ Dec. 2015: Accepted: $21^{\text {th }}$ Jun. 2016}

